\title{
Editors' Introduction: Introducing the New Team and Future Strategies
}

\author{
https://doi.org/10.19195/1899-5101.13.1(25).1
}

The year 2019 was important for the Central European Journal of Communication (CEJC) communities. With an anniversary conference in Wrocław (November 2018) we marked the beginning of the second decade of the CEJC. We are aware of several challenges faced by scientific journals in the data-driven, user-centered and transmedia environment. We know that our organizational adaptation to fastchanging societies (and technologies) will be critical to maintain our objectives and deliver scientific research. Therefore, over the last couple of months, we took part in consultations and meetings on future strategies for the CEJC. Through participation in roundtable discussions in Wrocław (2018) and Warsaw (2019), we identified key strategies to move forward, namely as Quality, Network, and Communication. Mapping of more specific goals in three key areas further helped us to renew editorial policies and to flatten our organizational structure.

On September 20th, 2019, we took over the role of Editors of the Central European Journal of Communication. We would like to thank all the members of the General Assembly of the Polish Communication Association (PCA) who gave their support and voted for the new Editor-in-Chief. We take these new responsibilities as a great honor and a challenge; we will continue working hard to deliver our mission and to transform the Central European Journal of Communication into a network of media and communications researchers.

We are also happy that Róża Norström (University of Silesia in Katowice) and Julia Trzcińska (University of Wrocław) decided to continue their valued work on Network and Quality of submissions. We also welcome to our team Jacek Mikucki (University of Warsaw) and Dagmara Sidyk (University of Warsaw) who have taken important tasks in maintaining the journal's Quality (scientific database) and fostering digital Communication.

In addition to this, we have expanded our network by ten Associate Editors, who agreed to help us with review processes and editing future issues of the CEJC. We managed to create a highly diverse group of media specialists from a wide range of countries and media disciplines (media policy, journalism studies, media management, creative industries, and political communication): Svetlana Bodrunova (St. Petersburg University, Russia), Nicoleta Corbu (University of Political Studies 
and Public Administration in Bucharest, Romania), Márton Demeter (National University of Public Service in Budapest, Hungary), Karen Donders (Vrije Universiteit Brussels, Belgium), Tobias Eberwein (The Austrian Academy of Science/ Alpen-Adria University of Klagenfurt, Austria), Paulo Faustino (University of Porto, Portugal), Aleksandra Krstić (University of Belgrade, Serbia), Ulrike Rohn (Tallinn University, Estonia), Anda Rožukalne (Rīga Stradiņ̌̌ University, Latvia) and Martin Solík (University of SS. Cyril and Methodius in Trnava, Slovakia). We are sure that partnership systems based on engagement and collaboration with the Associate Editors (2020-2022) will have a positive impact on our values and missions. These will be followed by a collaboration with CEJC supporters from the Scientific Network: media and communication scholars from 24 countries.

Maintaining the CEJC's quality continues to be our priority. We plan to verify and expand indexing/abstracting in international scientific databases. Besides, as agreed by the Executive of the Polish Communication Association, the goal is to launch the online journal management system and the 'Online First' strategies. From the next issue, we also open-up new ways of contributing to the CEJC. In addition to Scientific Papers and Book Reviews, you will now have an opportunity to submit a contribution to sections on Conference Reports and Interviews. We also want to draw your attention to a section entitled Methods and Concepts dedicated to theories, methodologies, or the experience in taking part in research initiatives.

We also plan to expand partnership relations with international scientific associations, scientific journals as well as media managers, policy-makers, and journalists. To foster visibility and findability of media and communications research we created a new CEJC website, where you can find all the issues published online, alongside information about our work (www.cejc.ptks.pl). Bearing in mind the importance of social networks we also invite you to follow all the CEJC news via Facebook (www.facebook.com/CEJCjournal), LinkedIn (www.linkedin.com/cejcjournal) and our Instagram account, where CEJC is 'travelling around the world' (www.instagram.com/cejcjournal).

The Spring 2020 issue of the Central European Journal of Communication was edited jointly with Alicja Jaskiernia (University of Warsaw) - local organizer of the 5th Congress of the Polish Communication Association in Warsaw. In this volume, we publish papers by scholars from the Netherlands, North Macedonia, Poland, Romania, and Sweden. Also, the section on Methods and Concepts provides a critical examination of democracy and digital dissonance. Contribution by Barbara Pfetsch (Freie University of Berlin) was available online prior to the publication in print. Finally, we also invite you to read the transcription of Roundtable discussion on the future of scientific journals in the data-driven era. This issue also contains book reviews, three conference reports, and information about this year's edition of Media and Democracy Karol Jakubowicz Award.

Last, but not least, we would like to warmly congratulate Bogusława DobekOstrowska (University of Wrocław) who received Honorary Membership of the 
Polish Communication Association (September 2019). During the 5th Congress of the Polish Communication Association Bogusława Dobek-Ostrowska - the founder and Editor-in-Chief (2008-2019) - decided to step down from leading the Central European Journal of Communication. We hope to build on Bogusława's extensive knowledge, experience, and enthusiasm. We are grateful for her dedication and valued support over the last years.

Michat Głowacki

Editor-in-Chief

Agnieszka Stępińska

Executive Editor 